\title{
Computed Tomographic Scanning Measurement of Skull Bone Thickness in Patients with Chronic Tension Type Headache; Case Control Study
}

\section{Zaki Noah Hasan*}

Department of neurology, Alkindy College of Medicine, University of Baghdad, Box 47188 Jadiryah, Baghdad, Iraq

\begin{abstract}
Background: Myofascial nociception is important in tension-type headache. Skull bone thickness is the total thickness of diploe and the external and internal tables.

Objective: To assess the thickness of occipital and temporal bone measured on brain axial CT scan in patient with chronic tension type headache and to compare the results with healthy age and sex matched control group.

Patients and method: a cross-sectional/case- control study; conducted in Neurosciences and Baghdad teaching hospitals between June 2010 and June 2011. The study including 209 individuals; 105 [46 male/59 female] had chronic tension headache and 104 [55 male/49 females] were a normal control group, the mean of the age were 49.250 and 46.047 years in both groups respectively. CT examination of Bone window images of the skull was taken. The thickness of the anterior part of right temporal bone body and the occipital bone were assessed

Results: The means of occipital bone thickness was 0.95714 and $1.1042 \mathrm{~mm}$ in the control and tension headache groups respectively; it was higher than the mean of temporal bone thickness which was 0.53750 and 0.72540 in the control and tension headache groups respectively.

Discussion and conclusion: The present study showed thicker skull in males; it was not approaching a statistical significant differences there was significantly thicker occipital and temporal skull bones in patients suffering from chronic tension headache in comparison to normal control group.
\end{abstract}

Keywords: Skull thickness; Tension headache

\section{Introduction}

Tension-type headache (TTH) is the most common primary headache disorders [1]. Chronic tension headache is a tension type headache that appears more than 15 days per month [2]. Pathophysiologically myofascial nociception is important in episodic tension-type headache; however, central mechanisms (i.e., central sensitization) are preponderant in the pathophysiology of the chronic form [2]. The measurement of the human skull based on CT images results are of great practical value in the fields of anatomy, clinical medicine, biomechanics study and head injury analysis [3]. The total skull bone thickness is the total thickness of diploe and the external and internal tables. Numerous studies have been used different radiological tests for assessment of cranial thickness like A-mode ultrasound, CT and MRI. The thickness and the breadth of the human skull are variable; and in general females have thicker skulls than males [4]. There was no correlation between total cranial vault thicknesses with sex, age or body weight [5]. There were no previous trials correlating tension headache and the thickness of the skull vault.

The aim of this research is to assess the thickness of occipital and temporal bone measured on brain axial CT scan in patient with chronic tension type headache and to compare the results with healthy age and sex matched control group.

\section{Patients and Methods}

The study including 209 individuals; 105 [46 male/59 female] had chronic tension headache and 104 [ 55 male/49 females] were a normal control group from the medical staff of the hospital and patients companions. The mean of the age were 49.250 and 46.047 years in both groups respectively. The study was done as cross-sectional study in the outpatient clinic in Baghdad Neurosciences and Baghdad teaching hospitals between June 2010 and June 2011.

The criteria for inclusion of chronic tension headache group were fulfilling international headache society criteria for the chronic tension headache [2]. The criteria for exclusion of tension headache group were any evidences of other headaches types like migraine, any bone disease like osteoporosis and osteomalacia, any hematologic disease associated with thickening of the bones and alcoholics patients. The above exclusion criteria were also applied on the control group.

Each patient was examined medically and neurologically by consultant neurologist and send for full blood count, blood film, serum electrolytes and brain CT scanning.

CT examination of Bone window images of the skull was taken using Aquilion 64 Slice Toshiba, Japan device; skull bone thickness was assessed by only one radiologist for all patients and controls.

Using the axial view of brain CT the thickness of the anterior part of right temporal bone body and the occipital bone midway between right mastoid bone and internal occipital protuberance were assessed using millimeter as unit of thickness.

*Corresponding author: Zaki Noah Hasan, Department of neurology, Alkindy College of Medicine, University of Baghdad, Box 47188 Jadiryah, Baghdad, Iraq Tel: +964-1-415-7006; E-mail: zaki_nooh@yahoo.com

Received December 02, 2011; Accepted April 23, 2012; Published April 26, 2012

Citation: Hasan ZN (2012) Computed Tomographic Scanning Measurement of Skull Bone Thickness in Patients with Chronic Tension Type Headache; Case Control Study. J Neurol Neurophysiol 3:128. doi:10.4172/2155-9562.1000128

Copyright: @ 2012 Hasan ZN. This is an open-access article distributed under the terms of the Creative Commons Attribution License, which permits unrestricted use, distribution, and reproduction in any medium, provided the original author and source are credited. 


\begin{tabular}{|c|c|c|c|c|c|c|c|}
\hline \multirow[t]{2}{*}{ Thickness millimeter } & \multicolumn{2}{|c|}{ Control patients } & \multirow{2}{*}{$\begin{array}{c}\text { Total } \\
\text { [Male }+ \text { female] } \\
\text { bone thickness } \\
N=104\end{array}$} & \multicolumn{2}{|c|}{ Tension headache } & \multirow{2}{*}{$\begin{array}{c}\text { Total } \\
\text { [Male }+ \text { female] } \\
\text { bone thickness } \\
N=105\end{array}$} & \multirow[t]{2}{*}{$\begin{array}{l}\mathrm{P} \text { value between } \\
\text { totals of both groups }\end{array}$} \\
\hline & $\begin{array}{l}\text { Male } \\
N=55\end{array}$ & $\begin{array}{l}\text { Female } \\
\mathrm{N}=49\end{array}$ & & $\begin{array}{l}\text { Male } \\
\mathrm{N}=46\end{array}$ & $\begin{array}{l}\text { Female } \\
\mathrm{N}=59\end{array}$ & & \\
\hline $\begin{array}{l}\text { Occipital bone } \\
\text { mean [standard } \\
\text { deviation ] }\end{array}$ & $\begin{array}{c}1.0121 \\
{[0.25219]}\end{array}$ & $\begin{array}{c}0.92250 \\
{[0.28955]}\end{array}$ & $\begin{array}{c}0.95714 \\
{[0.27575]}\end{array}$ & $\begin{array}{c}1.2100 \\
{[0.26437}\end{array}$ & $\begin{array}{c}1.0125 \\
{[0.23278]}\end{array}$ & $\begin{array}{c}1.1042 \\
{[0.25761}\end{array}$ & $\begin{array}{l}\text { The two-tailed } P \text { value } \\
\text { is less than } 0.0001 \\
\qquad \begin{array}{l}t=3.9844 \\
\text { df }=207\end{array}\end{array}$ \\
\hline $\begin{array}{l}\text { Temporal bone } \\
\text { mean [standard } \\
\text { deviation ] }\end{array}$ & $\begin{array}{c}0.6000 \\
{[0.17638]}\end{array}$ & $\begin{array}{c}0.4750 \\
{[0.067566]}\end{array}$ & $\begin{array}{c}0.53750 \\
{[0.13934]}\end{array}$ & $\begin{array}{c}0.72424 \\
{[0.29158]}\end{array}$ & $0.4750[0.067566]$ & $\begin{array}{c}0.72540 \\
{[0.28623]}\end{array}$ & $\begin{array}{l}\text { The two-tailed } P \text { value } \\
\text { is less than } 0.0001 \\
\qquad \begin{array}{c}t=6.0247 \\
d f=207\end{array}\end{array}$ \\
\hline $\begin{array}{l}\text { P valueOccipital / } \\
\text { temporal bone }\end{array}$ & & & $\begin{array}{l}P \text { value is less } \\
\text { than } 0.0001\end{array}$ & & & $\begin{array}{c}P \text { value is less } \\
\text { than } 0.0001\end{array}$ & \\
\hline Mean of Age & 49.939 & 41.881 & 46.047 & 52.400 & 52.400 & 49.250 & \\
\hline
\end{tabular}

$\mathrm{N}=$ number of patients $\mathrm{t}=\mathrm{t}$ test $\quad \mathrm{df}=$ degree of freedom

Table 1: The mean and standard deviation of occipital and temporal bone thickness in the tension headache group and control groups.

Statistical analysis was done using Graph Pad Quick Calcs: free statistical calculators means and the standard deviations were done; then comparison of the 2 groups' means was done using unpaired t test with $\mathrm{p}$ value considered significant when it is lesser than 0.05 .

\section{Results}

The thickness of both temporal and occipital bones in both groups showed higher results in males although this difference is not statistically significant (Table 1).

The thickness of occipital bone was 0.95714 and 1.1042 in the control and tension headache groups respectively. [ $p=$ less than 0.0001] (Table 1).

The thickness of temporal bone were 0.53750 and $0.72540 \mathrm{~mm}$ in the control and tension headache groups respectively $[\mathrm{p}=$ less than 0.0001] (Table 1).

The means of occipital bone thickness was 0.95714 and $1.1042 \mathrm{~mm}$ in the control and tension headache groups respectively; it was higher than the mean of temporal bone thickness which was 0.53750 and $0.72540 \mathrm{~mm}$ in the control and tension headache groups respectively (Table 1).

\section{Discussion}

Skull bone consists of the inner table, outer table and the middle layer or diploe of cancellous bone type [6]. Estimation of skull bone thickness using computed tomography (CT) scans has previously been studied in correlation to age and gender. Earlier studies of the human total cranial vault thickness found no correlation with sex, age or body weight [5]. Measurement of bone thickness by CT scanning was done by Li et al. [3], Gregory et al. [6], Pillai et al. [7] studies. Anterior portion of most female crania is thicker than male crania; however the male crania are thicker posterior skulls [8].

The present study showed a statistically greater thickness of the occipital bone than the temporal bone thickness. These results are in agreement with Li et al. [4] study. The present study showed an occipital bone thickness in the control group of 1.01 and $0.92 \mathrm{~mm}$ in male and female respectively while $\mathrm{Li}$ et al. [4] study showed average skull vault thickness of 0.756 and $0.817 \mathrm{~cm}$ in male and female respectively; those results was lesser than the results of the present study and this is also was found between the parieto occipital thickness between the blacks and whites American [9], and between the blacks and whites in Rhodesia [10]. This difference was related to biological ethnic factors differences and may be related to sunny environment and long summer in Iraq leading to thicker bone. Long and low cranial bones were more liable for strain necessating the need for greater thickness as an adaptation against strain [11].

Although the present study showed thicker skull in males; it was not approaching a statistical significant differences in thickness of both temporal and occipital bones in males and females; this results was in accordance with Lynnerup et al. [12], Hatipoglu et al. [13] and this was not agreeing with Li et al. [4] study. Roche [14] concludes that the anterior portion of most female crania is thicker than male crania; however the male crania are thicker posterior skulls.

The present study is the first attempt to find any relationship between thickness of the skull and the chronic tension headache. Chronic tension headache is the commonest headache type seen in the general medical practice $[1,2]$.

The pathogenic mechanism of the tension headache development was still unclear at present; it was assumed to be correlated with central pain processes $[1,2]$.

The present study showed a significantly thicker occipital and temporal skull bones in patients suffering from chronic tension headache in comparison to normal control group. Thicker skull vault in chronic tension headache maybe one of mechanical causes that lead to chronification of the tension type headache.

\section{Conclusion}

Thicker total skull bone was seen in occipital bone more than the temporal bone, and greater skull thickness results was seen in males more than females and the thickness measured by brain CT scan of the skull bones was greater in patients with chronic tension headache than the results of the normal control group.

\section{References}

1. Cathcart S, Winefield AH, Lushington K, Rolan P (2010) Stress and tensiontype headache mechanisms. Cephalalgia 30: 1250-1267.

2. http://www.medicalcriteria.com/criteria/med_headache.htm 
Citation: Hasan ZN (2012) Computed Tomographic Scanning Measurement of Skull Bone Thickness in Patients with Chronic Tension Type Headache; Case Control Study. J Neurol Neurophysiol 3:128. doi:10.4172/2155-9562.1000128

3. Li H, Ruan S, Peng X, Xie Z, Wang H, et al. (2007) The thickness measurement of alive human skull based on CT image. Sheng Wu Yi Xue Gong Cheng Xue Za Zhi 24: 964-968

4. Li H, Ruan J, Hao WZ, Wengling L (2007) Investigation of the critical geometric characteristics of living human skulls utilising medical image analysis techniques. International Journal of Vehicle Safety 2: 345-367.

5. Lynnerup $N$ (2001) Cranial thickness in relation to age, sex and general body build in a Danish forensic sample. Forensic Sci Int 117: 45-51.

6. Gregory BA, Snow RD, Brogdon BG, Williams JP (1997) Value of bone window images in routine brain CT: Examinations beyond trauma. Appl Radiol 26.

7. Pillai P, Sammet S, Ammirati M (2008) Application accuracy of computed tomography-based, image-guided navigation of temporal bone. Neurosurgery 63: 326-332.

8. Moreira-Gonzalez A, Papay FE, Zins JE (2006) Calvarial thickness and its relation to cranial bone harvest. Plast Reconstr Surg 117: 1964-1971.

9. Adeloye A, Katten KR, Silverman FN (1976) Thickness of the normal skull in the American blacks and whites. Am J Phys Anthropol 43: 23-30.
10. Ross MD, Lee KA, Castle WM (1976) Skull thickness of Black and White races. S Afr Med J 50: 635-638.

11. Walter BS (2010) How the Shape of the Cranium Affects Cranial Vault Thickness. Undergraduate Honors Thesis. Department of Anthropology. University of Florida.

12. Lynnerup N, Astrup JG, Sejrsen B (2005) Thickness of the human crania diploe in relation to age, sex and general body build. Head Face Med 1: 13.

13. Hatipoglu HG, Ozcan HN, Hatipoglu US, Yuksel E (2008) Age, sex and body mass index in relation to calvarial diploe thickness and craniometric data on MRI. Forensic Sci Int 182: 46-51.

14. Roche AF (1953) Increase in cranial thickness during growth. Hum Biol 25 81-92.

15. Nemec SF, Donat MA, Mehrain S, Friedrich K, Krestan C, et al. (2007) CT-MR image data fusion for computer assisted navigated neurosurgery of temporal bone tumors. Eur J Radiol 62: 192-198. 